\title{
Numerical Evaluation of the Impact of Green Wall on the Outdoor Thermal Environment
}

\author{
Ming Jin ${ }^{1, a}$, Jiying Liu ${ }^{1, b}$ and Linhua Zhang ${ }^{1, c}$ \\ ${ }^{1}$ School of Thermal Engineering, Shandong Jianzhu University, Jinan 250101, China \\ aminggold@163.com, bj.y.liu@hotmail.com, ${ }^{c} 22849468 @ q q . c o m$
}

\begin{abstract}
Keywords: green wall, building layout, Computational Fluid Dynamic, thermal environment, wet
\end{abstract} black globe thermometer.

\begin{abstract}
Green Wall has an important effect on the outdoor thermal environment quality and the thermal comfort of pedestrian. Rational layout and green design can effectively alleviate the negative impact of "Heat Island", reducing the heating and air conditioning energy consumption of the buildings. This paper established building models with different type of layouts, and Computational Fluid Dynamic (CFD) technology is carried out to study the effects of different layouts of buildings and Green Wall distribution on the thermal environment on the basis of wet black globe thermometer (WBGT) index.
\end{abstract}

\section{Introduction}

Various large-scale residential area and supporting facilities continue to be built as the acceleration of urbanization and residential quarters gradually concentrated. Affected by changes in the structure of city underlying surface and the influence of various factors such as anthropogenic exothermic ,"Heat Island" and its negative effect is increasingly protruding. Rational layout and green design can effectively reduce the heat island effect, green walls which can use the building envelope itself to arrangement green, without the need to take additional land for residential quarters, belongs to unconventional green system. Most of the current planning standards and design guidelines, will not introduce "green rate" as a provision indicators ${ }^{[1]}$.

Green wall can absorb and reflect the solar radiation. The green shading effect can reduce the wall temperature and the indoor temperature because the net radiation heat of the green wall is far less than that without green wall. The research from Peck ${ }^{[2]}$ shows that: green wall can make the wall temperature range from $10{ }^{\circ} \mathrm{C} \sim 60{ }^{\circ} \mathrm{C}$ to $5{ }^{\circ} \mathrm{C} \sim 30{ }^{\circ} \mathrm{C}$ in summer. Alexandri ${ }^{[3]}$ carried out the measurement about green wall in Hong Kong, as a result, the green wall can reduce surface temperature up to $8.4{ }^{\circ} \mathrm{C}$. In domestic, Lin Borong ${ }^{[4]}$ studied the influence and characteristics of the outdoor thermal environment that that underlying surface reflectance, the rate of evaporation and other parameters have influence on. Liu Yanfeng ${ }^{[5]}$ carried out a continuous testing of the thermal environment about a room with vertical green on the west wall in a city of central China. The average temperature of the outer surface of the wall dropped by $4.9^{\circ} \mathrm{C}$. Overall, greening can relieve the high temperature environment under certain conditions because of its better heat transfer performance. This paper use PHOENICS to study the influence of intensity of solar radiation, different layout of buildings, building green ratio on the comfort of outdoor thermal environment and the building surface temperature at 14:00.

\section{Establishment of Model}

Physical Model. Three different layout of buildings is designed in this study: determinant layout, staggered layout, synthetical layout. As shown in figure 1: a small cube of $10 \times 10 \times 10$ (Unit: m) represents a single building. The spacing all around the building is $10 \mathrm{~m}$. The green rates were designed to $0.2,0.3,0.4,0.5$. Concrete model (synthetical layout for example) are shown in figure 2 below: 


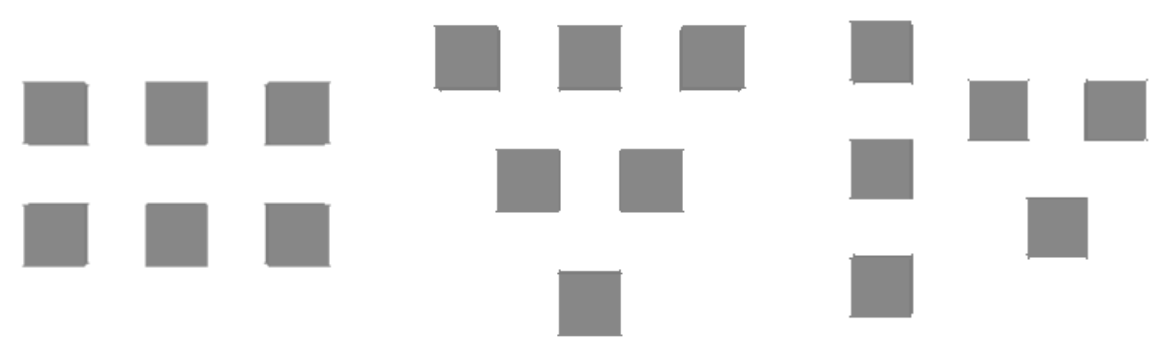

(a)

(b)

(c)

Fig 1 A plan view of the building layout (a :determinant layout, b: staggered layout, c:

synthetical layout)

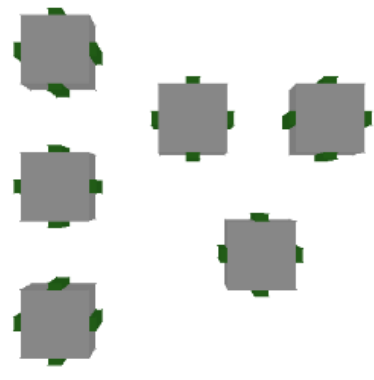

(a)

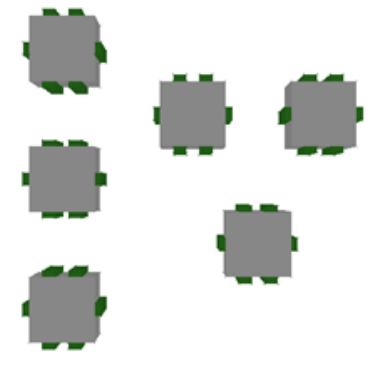

(b)

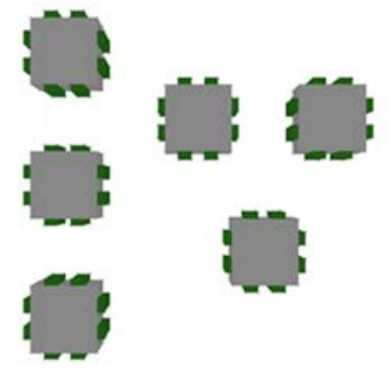

(c)

Fig 2 A plan view of green design of synthetical layout (a: $20 \%$ green tatio, b: $30 \%$ green ratio, c: $40 \%$ green ratio )

Turbulence Model. The heat transfer and air flow for the outdoor thermal environment is a very complicated process. Related physical phenomena includes air flow, solar radiation long-wave radiation between the building surface and ground, outdoor air heat transfer convection, solid heat conduction heat storage of the city underlying surface and building palisade structure.

Computational Fluid Dynamic (CFD) method based on Reynolds-averaged Navier-Stokes equations (RANS) model is commonly used in the field of building environment. In order to address the shortcomings of the standard k- $\varepsilon$ two equation model, Yakhel and Orszag of Princeton University put forward the RNG k- $\varepsilon$ model, in which the small scale movement systematically is removed from the control equation through reflect the influence of the small scale in large scale and the revised viscosity item. The model equation is as follows:

continuity equation:

momentum equation:

$$
\frac{z_{p}}{\partial s}+\nabla\left(\rho u_{t}\right)=0
$$

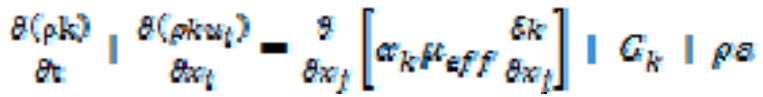

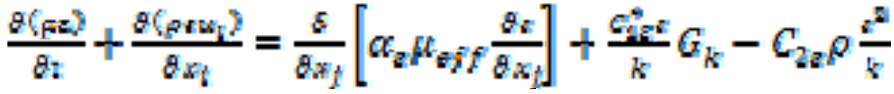

energy equation:

$$
\frac{\partial T}{\partial \tau}+\frac{\partial \omega_{i} T}{\partial x_{l}}=\frac{1}{\rho \theta_{g}} \frac{\partial}{\partial x_{l}}\left(\lambda \frac{\partial T}{\partial x_{i}}\right)+\frac{\partial}{\partial x_{l}}\left(-\overline{u_{f}^{i} T}\right)+q
$$

among these equations:

$$
\begin{aligned}
& \mu_{e s f}=\mu+\mu_{\varepsilon} ; \beta_{\tau}=\rho C_{p k} \frac{k^{g}}{2} \\
& C_{1 z}^{*}=C_{1 z}-\frac{\eta\left(1-\eta \eta_{\alpha}\right)}{1+\beta \eta^{2}} ; \mathrm{rl}-\left(2 E_{i j}^{n} E_{i j}\right)^{1 / 2} \frac{k}{a} \\
& E_{i j}=\frac{1}{2}\left(\frac{\partial w_{i}}{\partial x_{i}}+\frac{\partial w_{i}}{\partial x_{i}}\right) ; C_{\mu}=0.0845
\end{aligned}
$$

$C_{p k}=0.0845, \alpha_{k}=\alpha_{z}=1.39, \eta_{0}=4.377, \beta=0.012, C_{1 \varepsilon}=1.42, C_{S e}=1.68$.

Radiation Model. The city underlaying surface's solar radiation reflectivity has important influence on the outdoor thermal environment. It will affect the air temperature, relative humidity, 
radiation temperature. The study selected IMMERSOL, proved to be high accuracy and economy, as the radiation model. The model equation is as follows:

among the equation:

$$
\varepsilon \frac{d T}{d t}-\Delta(\lambda \times g r G h)=q
$$

c-specific heat capacity of solids, $\mathrm{W} / \mathrm{Kg}{ }^{\circ} \mathrm{C}$;

$\lambda$-thermal conductivity of a solid, $\mathrm{W} / \mathrm{m}{ }^{\circ} \mathrm{C}$;

q-heat flux per unit volume, $\mathrm{W} / \mathrm{m}^{3}$;

T-absolute temperature of the solid inside, $\mathrm{K}$;

t -time, s;

air temperature differential equation between solid:

among the equation:

$$
\Delta\left[\frac{1}{\operatorname{\alpha rg}\left(\alpha+a+\frac{1}{L_{0}}\right)} \times \operatorname{grad} E_{g}\right]=(\alpha+a)\left(E_{12}-\vec{E}_{32}\right)
$$

$F_{\mathrm{g}}$-radiation of air, $\mathrm{W} / \mathrm{m}^{2}$;

$E_{12}$-blackbody radiation between the two wall surfaces, $\mathrm{W} / \mathrm{m}^{2}$;

$\alpha$-absorption rate; $\varepsilon$--Emission rate;

$L_{a}$-distance between the adjacent sides of siding, m:

As, $E_{3}=\sigma_{0} T^{4}, d E_{3}=4 \sigma_{0} T^{5} d T$, differential equation (1-9) can be simplified as follows:

$$
\Delta\left(\lambda_{r} \times \operatorname{grad} T_{g}\right)=(\alpha+\varepsilon)\left(E_{12}-\sigma_{0} T^{4}\right)
$$

among the equation: $\lambda_{p}=\frac{\frac{a b}{\varepsilon} \sigma_{0} \tau^{3}}{a+a+\frac{L}{L_{d}}}, \sigma_{0}=5.67 \times 10^{-9}, \mathrm{~W} / \mathrm{m}^{2} K^{4}$ 。

\section{Thermal Environment Evaluation Index}

The paper introduce wet black globe thermometer (WBGT) index to evaluate the quality of outdoor thermal environment. WBGT is an index to react thermal environment, it consists of dry bulb temperature $T_{a}$ and wet bulb temperature under natural ventilation (not air) $T_{\text {nwb }}$ and black ball temperature $T_{g}$. In the United States, the National Association of Occupational Safety and Health (NIOSH) provides the standard of the thermal stress limit (NIOSH 1986). Table 1 is reference values

\begin{tabular}{|c|c|c|c|c|c|}
\hline \multirow{2}{*}{$\begin{array}{l}\text { Metabolism } \\
\text { level }\end{array}$} & \multirow{2}{*}{$\begin{array}{l}\text { Metabolism rate } \mathrm{M} \\
\qquad\left(\mathrm{W} \cdot \mathrm{m}^{-2}\right)\end{array}$} & \multicolumn{4}{|c|}{ Reference values of WBGT $\left({ }^{\circ} \mathrm{C}\right)$} \\
\hline & & \multicolumn{2}{|c|}{$\begin{array}{c}\text { A man who has a good heat } \\
\text { acclimation }\end{array}$} & \multicolumn{2}{|c|}{$\begin{array}{l}\text { A man who has a bad heat } \\
\text { acclimation }\end{array}$} \\
\hline 0 & $\mathrm{M}<117$ & \multicolumn{2}{|c|}{33} & \multicolumn{2}{|c|}{32} \\
\hline 1 & $117<\mathrm{M}<234$ & \multicolumn{2}{|c|}{30} & \multicolumn{2}{|c|}{29} \\
\hline 2 & $234<\mathrm{M}<360$ & \multicolumn{2}{|c|}{28} & \multicolumn{2}{|c|}{26} \\
\hline & & $\begin{array}{l}\text { Don't feel the } \\
\text { air flow }\end{array}$ & $\begin{array}{l}\text { Feel the air } \\
\text { flow }\end{array}$ & $\begin{array}{l}\text { Don't feel the } \\
\text { air flow }\end{array}$ & $\begin{array}{l}\text { Feel the air } \\
\text { flow }\end{array}$ \\
\hline 3 & $360<\mathrm{M}<468$ & 25 & 26 & 22 & 23 \\
\hline 4 & $M>468$ & 23 & 25 & 18 & 20 \\
\hline
\end{tabular}
of WBGT recommended by ISO 7243.

Table 1 Reference values of WBGT (from ISO 7243)

\section{CFD Simulation and Results Analysis}

CFD Simulation. "BLOCK" model of ground, buildings, green and "SUN" solar radiation model is built in PHOENIC. The article takes the average building height $\mathrm{H}$ as benchmark unit length of buildings and calculation area boundary. The specific boundary conditions are shown in the following table: 
Table 2 CFD simulation Settings

\begin{tabular}{|c|c|c|}
\hline \multicolumn{2}{|c|}{ Classification } & Content \\
\hline \multirow{3}{*}{ simulation area } & upstream area & entrance $5 \mathrm{H}$ \\
\hline & downstream area & exit $5 \mathrm{H}$ \\
\hline & both and top sides of the area & both side $5 \mathrm{H}$ \\
\hline \multirow{2}{*}{ wall condition } & surface function & Log Law \\
\hline & dimensionless number & $30<y+<500$ \\
\hline \multirow{2}{*}{ mesh } & grid distribution & $150 \times 150 \times 50$ \\
\hline & grid analysis & hexahedral structured grid \\
\hline \multirow{4}{*}{ boundary condition } & inlet boundary & $\begin{array}{l}\text { WIND boundary; } U=2 \mathrm{~m} / \mathrm{s} \text {; wind } \\
\text { direction: South; Power law a=0.14 }\end{array}$ \\
\hline & Outlet boundary & OUTLET \\
\hline & Wall condition & smooth surface \\
\hline & both and top sides of the area & symmetric boundary \\
\hline discrete algorithm & Algorithm to choose & SIMPLE \\
\hline
\end{tabular}

Analysis of Building Surface Temperature As shown in figure 3 and figure 4: the exterior wall's surface temperature of different building orientation changes with height. The surface temperature of the green wall is low than the same area without green, the most affected building by green is the west wall, in terms of individual buildings, the bottom surface temperature of the building is higher than that of the other floors $2{ }^{\circ} \mathrm{C} \sim 5^{\circ} \mathrm{C}$ at $14: 00 \mathrm{~h}$.
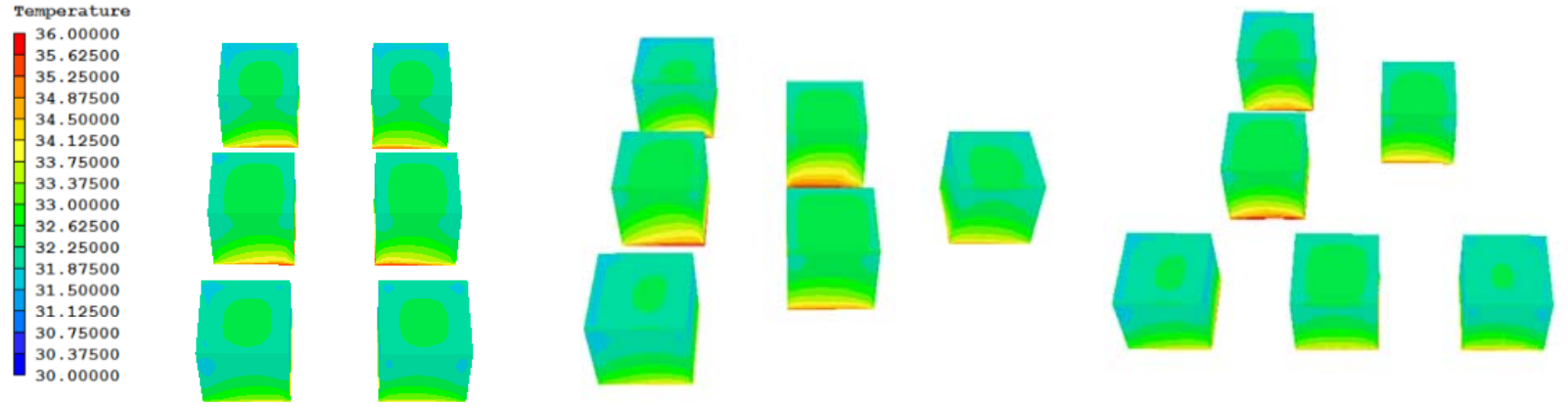

Fig 3 Surface temperature of building without green wall (a :determinant layout, b: staggered layout, c: synthetical layout)
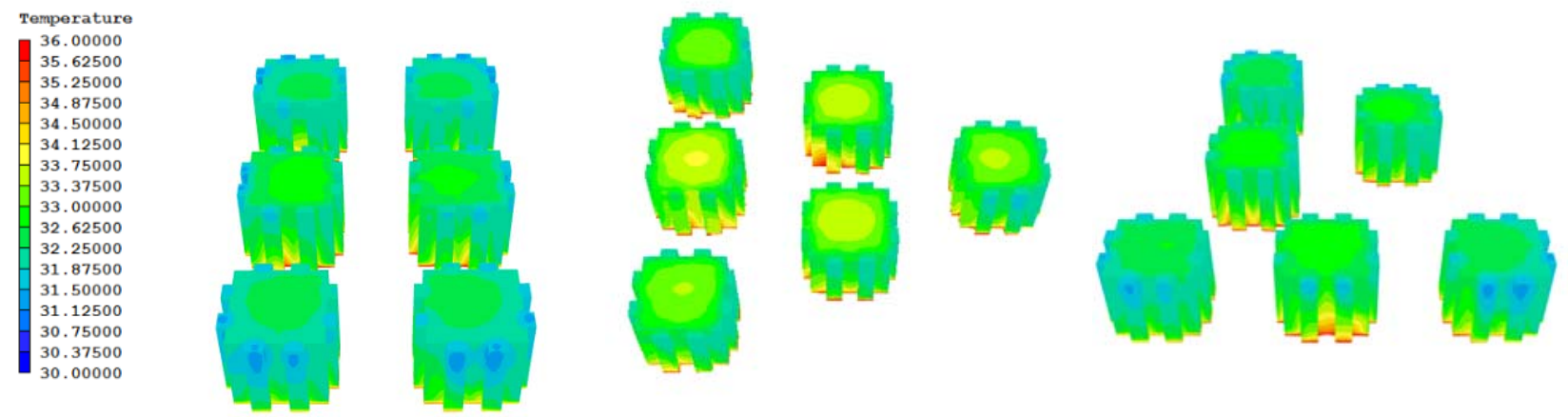

Fig 4 Surface temperature of building with green ratio of 40\% (a :determinant layout, b: staggered layout, c: synthetical layout)

The study about different building green rate (synthetical layout for example) of $20 \%, 30 \%, 40 \%$, $50 \%$, show that not only the surface temperature of the building west wall has been effectively improved, other building orientation's surface temperature has also been reduced after increasing the green rate of the west wall. The surface temperature of west wall with green rate of $50 \%$ is lower than 
that of $20 \%$ of $2{ }^{\circ} \mathrm{C} \sim 3{ }^{\circ} \mathrm{C}$, than that of $40 \%$ of $1{ }^{\circ} \mathrm{C} \sim 2{ }^{\circ} \mathrm{C}$. Therefore, the construction of green wall design should focus on the green design of the west wall, in particular, to strengthen the bottom cooling measures. The picture of result is shown in figure 5 below.
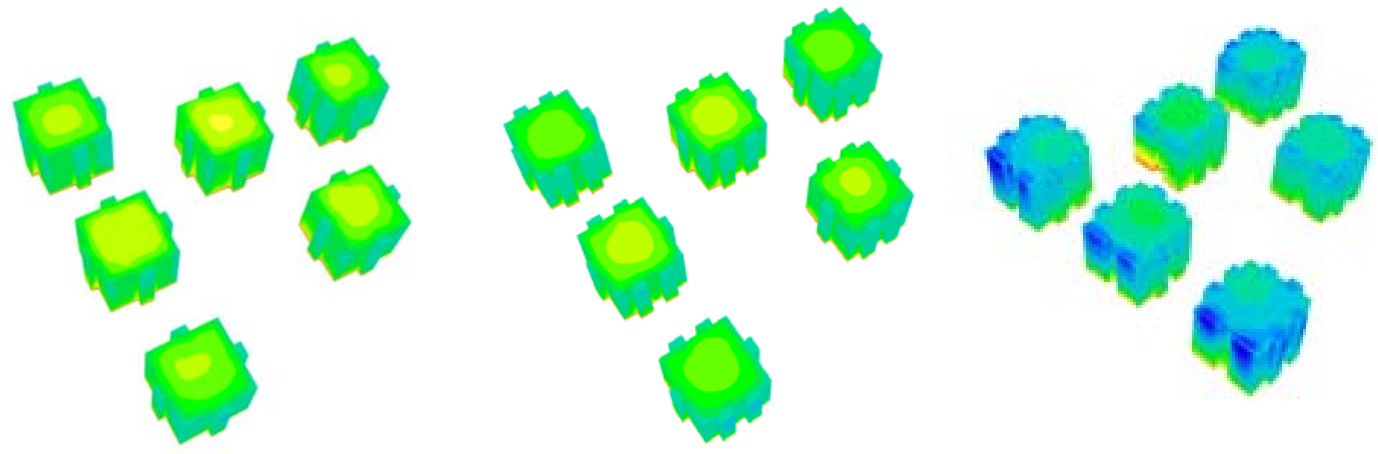

Fig 5 Surface temperature of building under synthetical layout (a: 20\% green ratio, b: $30 \%$ green ratio, c: $50 \%$ green ratio)

Comfort Analysis of Outdoor Thermal Environment Taking the comprehensive layout as an example, the cloud image of WBGT was intercepted at the height of $1.5 \mathrm{~m}$. Through the analysis of three different building layouts of the outdoor WBGT, it is found that the ventilation effect of the synthetical layout was the best, and the outdoor WBGT index distribution was uniform and WBGT $<32{ }^{\circ} \mathrm{C}$. The regulating action of green performance significant near the green wall, for example: in the vicinity of the green wall, the WBGT index of $50 \%$ green rate lower than that of $20 \%$ of $0.5^{\circ} \mathrm{C} \sim 2{ }^{\circ} \mathrm{C}$. After increasing the green rate of the west wall, the WBGT decreased surrounding the areas of the construction group, however, the WBGT index of internal space of the building group has little change. At the same time, the existence of vertical green increased the irregularity of the building surface, as a result, the WBGT index nearby the surface of the corner between the vertical green and the outer wall is higher than the area of smooth surface. WBGT cloud images of different green rates as shown in Figure 6 and figure 7:
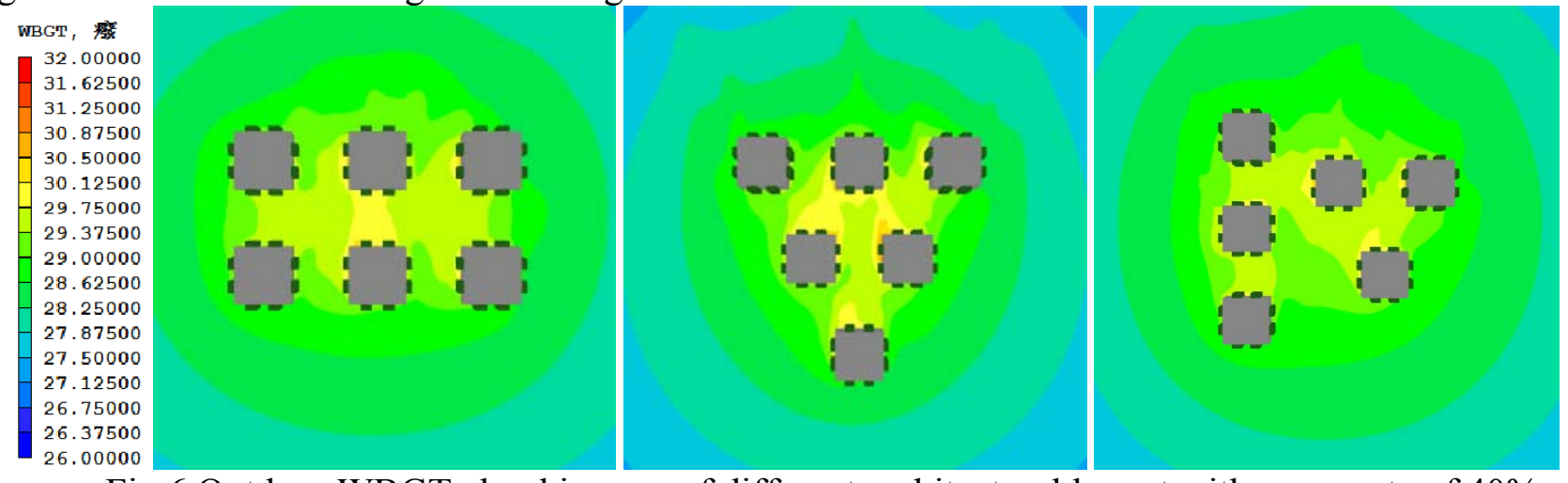

Fig 6 Outdoor WBGT cloud images of different architectural layout with green rate of $40 \%$ (a :determinant layout, b: staggered layout, c: synthetical layout) 

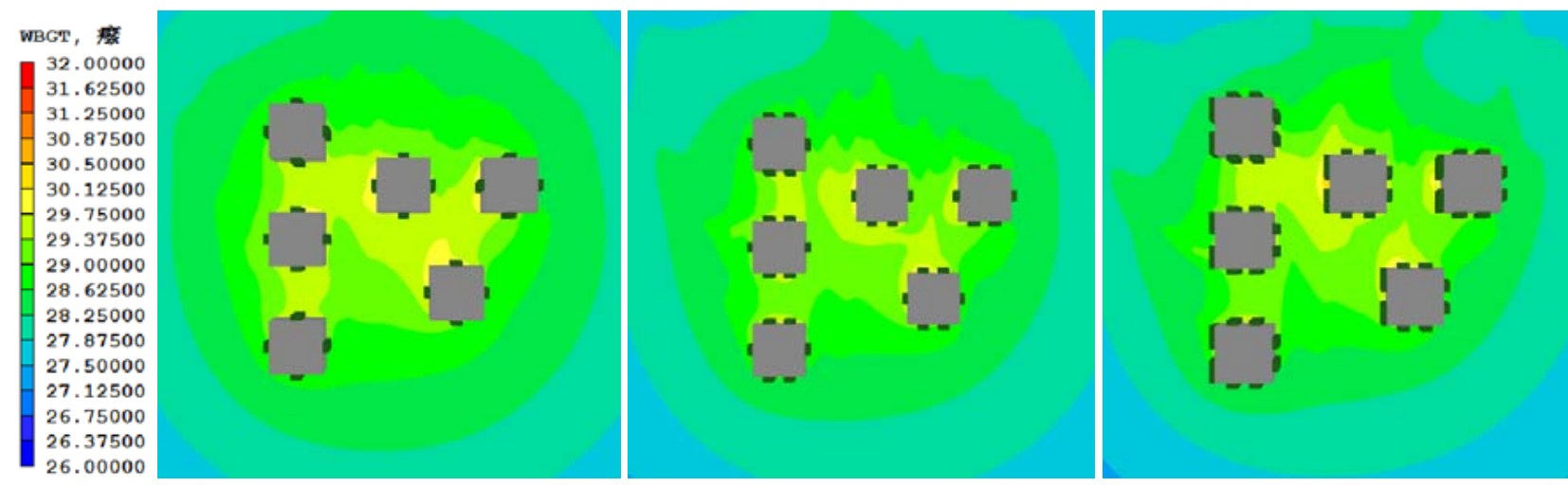

Fig 7 Outdoor WBGT cloud images of synthetical layout with different green ratio (a: 20\% green ratio, b: $30 \%$ green ratio, c: $50 \%$ green ratio)

\section{Summary}

Through the study of the surface temperature of the exterior wall and the outdoor thermal environment of the building under different building layouts and different green rate of exterior wall, the research found that: green wall can effectively reduce the surface temperature of the building, and improve the outdoor thermal environment. In order to achieve a better cooling effect, in the process of building planning and designing should use the integrated layout of the loose form as far as possible, to strengthen the effect of natural ventilation. In addition, increasing the green rate of the west wall of the building and near the ground can effectively improve the surface temperature of the buildings. The article introduces the WBGT index to analyze the outdoor thermal environment comfort. WBGT index is simple and easy to calculate, although it can be chosen as the evaluation index of outdoor thermal environment, however, it is difficult to evaluate the outdoor thermal environment accurately just use WBGT as the evaluation index only. In the future research, it is necessary to make a comprehensive evaluation of WBGT combined with SET and other evaluation indicators. In the future research, it is necessary to introduce other evaluation indicators, and together with WBGT to assess the outdoor thermal environment, such as SET and MRT.

\section{Acknowledgement}

This study is sponsored by the Ministry of Science and Technology Planning Project (2011-K1-34), Science and Technology Project of Shandong Province (2011GNC11401, 2012GGX10416), and the Doctoral Research Fund Project (XNBS1408) award from the Shandong Jianzhu University. Authors would like to thank Li Liang and Wei Wang for their technical support during the preparation of this research.

\section{References}

[1] N.H.Wong, A.Yong, K. Tan, et al., Thermal evaluation of vertical greenery systems for building walls [J]. Building and Environment, 2010, 45: 663-672

[2] S.W. Peck, C. Callaghan, B. Bass, Greenbacks from green roofs: forging a new industry in Canada[R].Canada: Mortgage and Housing Corporation, 1999.

[3] E. Alexandri, P. Jones, Temperature decreases in an urban canyon due to green walls and green roofs in diverse climates [J]. Building and Environment, 2008, 43: 480-493.

[4] B. Lin. The impact of greening on the outdoor thermal environment research [D]. Beijing: Tsinghua university,2005. 
[5] Y. Liu, Y. Chen, D. Wang, etc. The vertical greening effect on indoor thermal environment test study [J]. Journal of Xi' an building University of science and technology: Natural science edition, 2015, 47(3):423-426.

[6] W. Lu, J. Chen, Study on Influences of Modular Three-dimensional Greening on Building Energy Conservation [J]. Building Science, 2012, 28(10): 46-50. 